\title{
Positive Activities as Protective Factors Against Mental Health Conditions
}

\author{
Kristin Layous, Joseph Chancellor, and Sonja Lyubomirsky \\ University of California, Riverside
}

\begin{abstract}
Applying Nolen-Hoeksema and Watkins's (2011) transdiagnostic risk factor heuristic to our work on positive activities (i.e., practices that characterize naturally happy people, like expressing gratitude and practicing generosity), we propose that such activities may serve as protective factors that mitigate proximal risk factors both directly and by intervening with the mechanisms that give rise to them. First, we discuss theoretical and empirical support for the importance of well-being and the mechanisms that explain how positive activities promote well-being (by boosting positive emotions, positive thoughts, positive behaviors, and need satisfaction; Lyubomirsky \& Layous, 2013). Second, we outline examples of how positive activities can mitigate two particular proximal risk factors (rumination and loneliness) and counteract environmental triggers (i.e., moderators) that might amplify them (e.g., through adaptive coping). Third, we argue that positive activities can be taught to youth to instill positive patterns of emotions, thoughts, and behaviors that may serve as protective factors over the course of their lifetimes. Lastly, we propose that certain positive activities might be particularly well-suited to certain individuals and to specific risk factors.
\end{abstract}

Keywords: positive activities, positive interventions, positive emotion, psychopathology, transdiagnostic risk factors

Happier people show less psychopathology (Diener \& Seligman, 2002). Although this finding may appear both obvious and redundant, the study of happiness offers novel directions for understanding how mental health conditions develop and how they might be derailed. Inspired by Nolen-Hoeksema and Watkins's (2011) transdiagnostic model of how specific risk factors lead to multiple disorders or symptom groups, we propose several ways by which happiness-increasing strategies (i.e., positive activities) can ultimately serve as protective factors against a variety of mental health conditions, by mitigating proximal risk factors and the processes that set those risk factors in motion. Based on prior research, we also suggest conditions under which positive activities can vary in their effectiveness and discuss how such activities may interact with individual differences and specific risk factors.

\section{Why Promote Well-Being?}

With mental disorders as one of the leading causes of disability worldwide (World Health Organization, 2004) and the majority of people going without the minimally recommended mental health treatment (National Institute of Health, 2008), why should researchers and practitioners focus on well-beingdefined as high life satisfaction and frequent positive affect (Diener, Suh, Lucas, \& Smith, 1999)_rather than devoting their energies and resources to investigating and ameliorating symptoms of disorder?

Kristin Layous, Joseph Chancellor, and Sonja Lyubomirsky, Department of Psychology, University of California, Riverside.

Correspondence concerning this article should be addressed to Kristin Layous, 900 University Avenue, Riverside, CA 92507. E-mail: klayo001@ ucr.edu
Drawing on the transdiagnostic model of psychopathology (Nolen-Hoeksema \& Watkins, 2011), we propose that attending to the promotion of well-being-over and above targeting distress - can improve overall mental health in two primary ways. First, intentionally cultivating well-being can reduce the frequency of negative emotions, negative behaviors, and negative thoughts that are characteristic of multiple risk factors for disorder, and thereby intervene in the process by which risk factors lead to psychopathology. Second, promoting well-being leads to positive outcomes in work, love, and health, which can help people manage and weather the conditions that may amplify the adverse effects of risk factors.

\section{Promoting Well-Being Can Reduce Negative Emotions, Negative Thoughts, and Negative Behaviors}

Research suggests that positive emotions-the hallmark of well-being-can serve as antidotes to negative emotions like sadness and anxiety, neutralizing their physiological aftereffects (e.g., cardiovascular reactivity; Fredrickson, Mancuso, Branigan, \& Tugade, 2000). In addition, positive emotions stimulate people to act and approach (rather than avoid) rewards and opportunities in their lives (Fredrickson, 1998, 2001). Thus, positive emotions may aid those feeling trapped or helpless in the midst of negative moods, thoughts, or behaviors-for example, grief, pessimism, or isolation-spurring them to take positive action. As a case in point, happy people are relatively less likely to engage in rumination (Lyubomirsky, Boehm, Kasri, \& Zehm, 2011). Increasing happiness may also help dampen the acute pain of a negative life event (e.g., bereavement, unemployment) or foster adaptive coping with acute stress, thus preventing a downward spiral into clinical levels of depression, anxiety, substance use, or other mental health conditions. 


\section{Promoting Well-Being Fosters Positive Life Outcomes}

During the last several decades, researchers have compiled a strong body of evidence that the presence of well-being confers a number of unique benefits for individuals that are not otherwise conferred by the absence of distress (De Neve, Diener, Tay, \& Xuereb, 2013; Lyubomirsky, King, \& Diener, 2005). A metaanalysis of 225 cross-sectional, longitudinal, and experimental studies demonstrated that happiness is associated with, precedes, and likely actually causes positive outcomes in the domains of work, relationships, and physical health (Lyubomirsky, King et al., 2005). For example, happier people earn higher supervisor evaluations at work, have relatively more friends, are more active and likable, and show stronger immune function.

The broaden-and-build theory of positive emotions explains in part why higher well-being leads to positive life outcomes (Fredrickson, 1998, 2001). Positive emotions broaden people's thinking and attention, encouraging creative solutions to problems and an urge to approach, act, play, and explore. When Jane feels good, she is likely to take actions that create or reinforce durable personal resources in her relationships (e.g., reaching out to a friend), health (e.g., visiting the gym), or work (e.g., applying for a job). Even when the pleasant feelings fade, such social, physical, and intellectual resources may linger, continuing to enhance her life and bolster her resilience against future mental health difficulties and general life challenges. Both the increased resources (e.g., social support) and the positive outcomes (e.g., fulfilling job) associated with greater well-being can mitigate the mechanisms by which distal risk factors give rise to proximal risk factors (e.g., low self-esteem or inability to cope), as well as preempt or temper the conditions that increase the likelihood that proximal risk factors result in disorder (e.g., loss, failure, or stress; see NolenHoeksema \& Watkins, 2011).

\section{Positive Activities as Protective Factors}

Individual differences in happiness are theorized to be influenced by individual differences in both genetics and life circumstances (Lyubomirsky, Sheldon, \& Schkade, 2005). However, just as distal risk factors for mental disorders (e.g., biology or early trauma) do not directly cause psychopathology (Nolen-Hoeksema \& Watkins, 2011), lacking optimal genes and circumstances does not preclude people from being happy. Instead, intermediary processes predict whether predispositions precipitate happiness-or mental disorder. The intermediary processes that we introduce here are "positive activities," such as thinking gratefully or acting prosocially, which have been shown to reinforce happiness in naturally happy people and to lead to greater happiness in those not advantaged by their circumstances or chromosomes (Lyubomirsky, 2001; Lyubomirsky, Sheldon et al., 2005; Sin \& Lyubomirsky, 2009).

We propose that such positive activities can act as proximal protective factors - that is, as critical intervening processes that explain why individuals with the same distal risk factors (e.g., biology or early trauma) develop divergent trajectories or no psychopathology at all (see Table 1 for a list and illustration). Specifically, we theorize that positive activities can (a) directly mitigate proximal risk factors (e.g., rumination or pessimism) for psychological disorders; (b) decrease the likelihood that distal risk factors lead to proximal risk factors by intervening with the mechanisms that give rise to them (e.g., maladaptive coping or negatively biased beliefs); or (c) mitigate the conditions that interact with risk factors to create symptoms (e.g., acute stress). In these ways, positive activities can ultimately protect individuals from mental health conditions. Table 1 illustrates these three mechanisms in Columns A, B, and C, respectively.

Table 1

Positive Activities as Protective Factors Within Nolen-Hoeksema and Watkins's (2011) Transdiagnostic Risk Factor Framework

(A)

Positive Activity

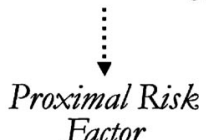

Factor

Positive activities mitigate proximal risk factors (e.g., rumination or loneliness)
(B)

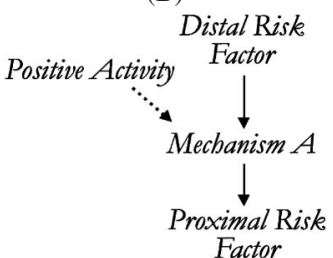

Positive activities mitigate mechanisms linking distal and proximal risk factors (e.g., negative self-view or obsession with body)
(C)

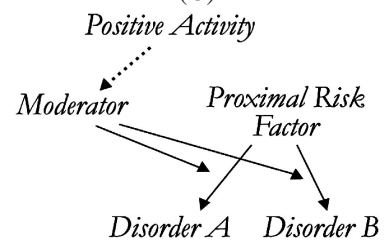

Positive activities mitigate moderators that act on proximal risk factors to determine disorder (e.g., loss or social stress)

\begin{tabular}{|c|c|c|}
\hline (1) Directly & Directly & Directly \\
\hline $\begin{array}{l}\text { (2) By boosting well-being } \\
\text { Via positive emotions } \\
\text { Via positive thoughts } \\
\square \text { Via positive behaviors } \\
\square \text { Via need satisfaction }\end{array}$ & $\begin{array}{c}\text { By boosting well-being } \\
\text { Via positive emotions } \\
\text { Via positive thoughts } \\
\text { Via positive behaviors } \\
\text { Via need satisfaction }\end{array}$ & $\begin{array}{c}\text { By boosting well-being } \\
\square \text { Via positive emotions } \\
\text { Via positive thoughts } \\
\square \text { Via positive behaviors } \\
\square \text { Via need satisfaction }\end{array}$ \\
\hline $\begin{array}{l}\text { (3) Via outcomes of well-being } \\
\text { In relationships } \\
\text { In work } \\
\text { In health }\end{array}$ & $\begin{array}{l}\text { Via outcomes of well-being } \\
\text { In relationships } \\
\text { In work } \\
\text { In health }\end{array}$ & $\begin{array}{l}\text { Via outcomes of well-being } \\
\text { In relationships } \\
\text { In work } \\
\text { In health }\end{array}$ \\
\hline
\end{tabular}




\section{What Are Positive Activities?}

Converging theoretical (Lyubomirsky, 2008; Lyubomirsky, Sheldon et al., 2005) and empirical (Sin \& Lyubomirsky, 2009) evidence persuasively suggests that people can intentionally and successfully raise their happiness levels. Researchers have theorized that people's intentional activities-how they choose to spend their time and how they respond to situations in their lives-account for a large part of their happiness (Lyubomirsky, Sheldon et al., 2005).

What types of intentional activities might increase a person's relative level of well-being? Initially, researchers studied naturally happy people to learn how their thoughts and behaviors reinforced their happiness (e.g., Diener et al., 1999; Lyubomirsky, 2001; Myers, 2000). For example, happy people have been found to exhibit such positive habits as thinking optimistically about their futures (Scheier \& Carver, 1993), being grateful for life's blessings (McCullough, Emmons, \& Tsang, 2002), savoring positive experiences (Jose, Lim, \& Bryant, 2012), and doing kind acts for others (Krueger, Hicks, \& McGue, 2001). Researchers posited that anyone could practice such positive activities for the same benefit. Validating these ideas, multiple randomized controlled trials have now shown that engaging in a variety of positive activities does indeed increase the practitioner's happiness (Sin \& Lyubomirsky, 2009).

Positive activities can take many forms. Practices shown to successfully increase well-being include (but are not limited to) writing letters of gratitude (Boehm, Lyubomirsky, \& Sheldon, 2011; Layous, Lee, Choi, \& Lyubomirsky, 2013; Lyubomirsky, Dickerhoof, Boehm, \& Sheldon, 2011; Seligman, Steen, Park, \& Peterson, 2005; Watkins, Woodward, Stone, \& Kolts, 2003), counting one's blessings (Chancellor, Layous, \& Lyubomirsky, 2013; Emmons \& McCullough, 2003; Froh, Sefick, \& Emmons, 2008; Lyubomirsky, Sheldon, et al., 2005; Seligman et al., 2005; Watkins et al., 2003), practicing optimism (Boehm et al., 2011; King, 2001; Layous, Nelson, \& Lyubomirsky, 2013; Lyubomirsky, Dickerhoof, et al., 2011; Sheldon \& Lyubomirsky, 2006), performing acts of kindness (Chancellor, Jacobs Bao, \& Lyubomirsky, 2013; Della Porta, Jacobs Bao, \& Lyubomirsky, 2012; Dunn, Aknin, \& Norton, 2008; Layous, Nelson, Oberle, SchonertReichl, \& Lyubomirsky, 2012; Sheldon, Boehm, \& Lyubomirsky, 2012, Study 2), using one's strengths in new ways (Seligman et al., 2005), affirming one's most important values (Nelson, Fuller, Choi, \& Lyubomirsky, 2013), and meditating on positive feelings toward self and others (Fredrickson, Cohn, Coffey, Pek, \& Finkel, 2008).

Positive activities are typically brief, simple, accessible, and require little to no financial resources. For example, people may be instructed to list "five blessings" or "three good things" once per week (Chancellor, Layous et al., 2013; Emmons \& McCullough, 2003; Lyubomirsky, Sheldon et al., 2005; Seligman et al., 2005). This positive activity is designed to induce gratitude and to jumpstart a routine of taking note or capitalizing on the positive aspects of one's life as opposed to focusing on negatives. Although positive activities have been successfully incorporated into talk therapy (Seligman, Rashid, \& Parks, 2006), they are self-administered in most positive intervention studies - that is, the participants receive the positive activity instructions online and engage in the activities at their convenience and on their own time.
A close analogue of positive activities that has been successfully employed in traditional therapeutic interventions is behavioral activation, a treatment approach to depression that aims to increase participation in "adaptive activities" (i.e., those associated with competence and pleasure), decrease behaviors that exacerbate depression, and overcome barriers in achieving the first two behavioral goals (Dimidjian, Barrera, Martel, Muñoz, \& Lewinsohn, 2011). Behavioral activation, which has its roots in behaviorism, primarily emphasizes behavior change, whereas positive activities can be behavioral (e.g., acts of kindness) or cognitive (e.g., visualizing a best possible self). Other differences between behavioral activation and positive activities lie in their target populations (i.e., clinical vs. nonclinical), the presence or absence of a therapist, and the degree of activity customization, with highly individualized plans in behavioral activation and standardized instructions in positive activities (e.g., perform three acts of kindness or write a gratitude letter).

\section{How Positive Activities Promote Well-Being}

Our positive activity model (Lyubomirsky \& Layous, 2013) proposes a specific set of mechanisms by which positive activities increase well-being. We posit that positive activities only boost an individual's well-being to the extent that they increase positive emotions, positive thoughts, positive behaviors, and psychological need satisfaction. For example, those who participated in a 7-week "loving-kindness" meditation training in which they learned to cultivate loving, compassionate feelings toward themselves and others showed increases in positive emotions relative to a waitlist control group (Fredrickson et al., 2008). These increases in positive emotions led to increases in personal resources such as social relationships and physical health that, in turn, predicted increases in overall life satisfaction.

Evidence for positive thoughts as a mediator comes from studies showing that practicing positive activities leads people to construe the events in their lives in a more positive light. For example, in one study, people reported their weekly experiences over the course of a 6-week positive activity (gratitude and optimism) intervention. Although those in the positive activity conditions (vs. the control condition) reported that their daily life events were becoming more and more positive during the intervention, independent coders detected no such shifts in positivity (Dickerhoof, 2007). Thus, participants who practiced the positive activity made relatively more positive appraisals of their life events that appeared to be independent of what actually transpired.

Positive activities also steer people to engage in other positive behaviors that are unrelated to the prescribed activity. In the same way that clusters of negative behaviors, such as binge eating and substance abuse, might be part of a downward spiral, clusters of positive behaviors may co-occur and reinforce one another in an upward spiral (Fredrickson \& Joiner, 2002). For example, people who counted blessings once per week for 10 weeks also spent more time exercising than people who recounted their daily hassles (Emmons \& McCullough, 2003).

Engaging in positive activities has also been shown to satisfy basic psychological needs such as autonomy (control), competence (efficacy), and relatedness (connectedness; Deci \& Ryan, 2000). In a 6-week intervention, participants who expressed gratitude and optimism increased in relatedness and autonomy to a greater 
degree than those who engaged in a neutral activity (Boehm, Lyubomirsky, \& Sheldon, 2012; see Chancellor, Jacobs Bao et al., 2013, for analogous results for competence). Furthermore, these increases in need satisfaction were associated with subsequent increases in life satisfaction. Another study randomly assigned participants either to work on increasing one of their psychological needs (autonomy, competence, or relatedness) or to improve their life circumstances (Sheldon et al., 2010). Participants who focused on improving their autonomy and relatedness showed increases in well-being relative to those who focused on improving life circumstances, thus supporting our assumption that psychological need satisfaction is an important path to well-being.

Applying our work to the clinical domain, we posit that the same mechanisms that have been shown to mediate the relationship between positive activities and well-being (positive emotions, positive thoughts, positive behaviors, and psychological need satisfaction) may protect against mental health conditions. Several examples of how this process may unfold are described in the next section.

\section{Positive Activities Mitigate Proximal Transdiagnostic Risk Factors}

Positive activities may protect against mental disorders by directly targeting risk factors associated with psychopathology. We argue that positive activities constitute a set of skills that one can summon to mitigate proximal risk factors for mental illness, as well as the processes that trigger and amplify them. Consistent with this approach, developmental psychologists propose that youth can be taught a set of core competencies (e.g., positive sense of self, prosocial connectedness, and self-control) that will prevent risk behaviors such as substance abuse, violence, and risky sexual behavior (Guerra \& Bradshaw, 2008; Weissberg, Kumpfer, \& Seligman, 2003). Similarly, we posit that positive activities (e.g., gratitude, savoring, kindness) can act as a toolkit for people to use when they are faced with negative patterns of thoughts and behaviors (i.e., the proximal risk factors and the mechanisms that trigger them, as described by Nolen-Hoeksema and Watkins, 2011; see Columns A and B of Table 1) or challenging life events, loss, and stress (i.e., the conditions-or moderators-that increase the likelihood that risk factors devolve into psychopathology and determine which symptoms a proximal risk factor will produce in a given individual; see Column C). In sum, we propose that positive activities ultimately protect against mental health conditions because they mitigate specific proximal transdiagnostic risk factors-both directly (see Table 1, Row 1) and by increasing wellbeing and its associated mediators (e.g., positive views of the self) and positive outcomes (e.g., strengthened relationships; see Rows 2 and 3 ).

Positive activities may come naturally to some individuals who, whether through biology, modeling, or inculcation, are predisposed to their use. However, such activities can also be practiced deliberately. Below we propose two examples of ways in which positive activities, and the resulting increases in well-being and its outcomes, modulate specific risk factors and the processes that operate on them, and, thus, the likelihood that they cause psychopathology (see Table 1).

\section{Positive Activities Can Interrupt Rumination}

Rumination-repetitively focusing attention on oneself and one's problems without taking action to resolve them (NolenHoeksema, 1991) — has been related to several types of psychopathology (Aldao, Nolen-Hoeksema, \& Schweizer, 2010). NolenHoeksema and Watkins (2011) proposed that rumination is a pivotal transdiagnostic proximal risk factor that predicts multiple disorders.

Experimental research has shown that rumination leads to a host of adverse cognitive and hedonic consequences. Dysphoric individuals who are prompted to ruminate endorse more negatively biased interpretations of hypothetical situations and are more pessimistic about future life events (Lyubomirsky \& NolenHoeksema, 1995), rate their troubles as more severe and unsolvable (Lyubomirsky, Tucker, Caldwell, \& Berg, 1999), generate less effective solutions to interpersonal problems (Lyubomirsky \& Nolen-Hoeksema, 1995), and recall more negative autobiographical memories (Lyubomirsky, Caldwell, \& Nolen-Hoeksema, 1998) than dysphoric individuals prompted to distract themselves. Notably, the cognitions of the distracted dysphoric people-who engage in relatively neutral tasks such as mentally rotating abstract figures or visualizing clouds forming in the sky-are generally indistinguishable from those of healthy nondysphoric people. If neutral distraction tasks are effective in thwarting rumination and its adverse effects, we reason that positive activities can also interrupt ruminative processes while providing a wealth of other benefits (see Table 1, Column A, Row 1).

For example, performing acts of kindness is an other-focused positive activity that could distract chronic ruminators and interrupt their maladaptive self-focus. Because acting prosocially also engenders positive thoughts (e.g., I am a caring person) and strengthens relationships, it can alleviate both the mechanisms (e.g., negative self-views) and moderators (e.g., social stress) of the process by which rumination can devolve into psychopathology (see Table 1, Columns B \& C and Rows 2 \& 3). Likewise, expressing gratitude can help ruminators achieve a broad, "big picture" perspective (e.g., whatever is troubling them this moment is trivial compared with their children or their health; Fredrickson, 2004). For example, gratitude has been found to improve body satisfaction among people who obsess about their body size (Geraghty, Wood, \& Hyland, 2010).

Another validated positive activity-affirming one's most important values - could improve Jim's self-view of being unable to cope to seeing himself instead as competent, good, capable, and in control of his life (Sherman \& Cohen, 2006; Steele, 1988), which might, in turn, reduce threatening self-doubts that could trigger ruminative episodes. Self-affirmation has also been found to reduce negative emotions and relatively increase need satisfaction, flow, and meaning in life (Nelson et al., 2013), as well as buffer physiological responses to stressful situations (Creswell et al., 2005; Sherman, Bunyan, Creswell, \& Jaremka, 2009), and boost academic outcomes (Cohen, Garcia, Apfel, \& Master, 2006; Cohen, Garcia, Purdie-Vaughns, Apfel, \& Brzustoski, 2009). Taken together, these benefits of one simple positive activity can intervene at multiple points of the risk-factor-to-disorder trajectory.

Notably, the positive emotions stimulated by positive activities can help people to creatively solve the problems they might be ruminating about (Isen, Daubman, \& Nowicki, 1987) or avert them 
from happening in the first place, thereby reducing opportunities for rumination (see Table 1, Column C). For example, doing acts of kindness can reduce or prevent social stress (directly) and decrease the likelihood of work or relationship problems (indirectly, though its impact on overall well-being). Lastly, research suggests that practicing such positive thoughts and behaviors over time can make them habitual (Ouellette \& Wood, 1998), thus replacing a maladaptive ruminative response style with a positive one.

\section{Positive Activities Inhibit Loneliness}

Loneliness is comorbid with many types of psychopathology, including depression, anxiety, social phobia, and eating disorders (Heinrich \& Gullone, 2006; Lasgaard, Goossens, Bramsen, Trillingsgaard, \& Elklit, 2011). Thus, feelings of closeness and connectedness with others (the conceptual foil of loneliness) conceivably protect against psychopathology by preempting this risk factor from precipitating disorder. As mentioned earlier, positive activities such as practicing gratitude and optimism lead to increases in connectedness, which fosters subsequent increases in well-being over time (Boehm et al., 2012). Furthermore, multiple studies have shown that expressing gratitude not only boosts feelings of connectedness but promotes relationship maintenance behaviors and satisfaction with existing relationships (Algoe, Gable, \& Maisel, 2010; Algoe, Haidt, \& Gable, 2008; Lambert \& Fincham, 2011; Wood, Maltby, Gillett, Linley, \& Joseph, 2008). In addition, youth prompted to perform kind acts exhibit stronger social ties in their classrooms (Layous et al., 2012).

Furthermore, increases in positive emotions that arose from the loving-kindness meditation intervention discussed earlier (Fredrickson et al., 2008) were most pronounced when people were later interacting with others, suggesting that the meditation practice fostered positive social interactions. Also, gains in positive emotions during the intervention period predicted increases in perceived social support and fulfilling relationships with others, demonstrating that positive emotions can lead to a cascade of positive relational outcomes. For example, people induced into a happy mood are more interested in social activities (Cunningham, 1988a), disclose more about themselves to others (Cunningham, 1988b), and perceive their relationships as closer (Waugh \& Fredrickson, 2006). In sum, research suggests that positive activities promote positive relationships with others, which may mitigate interpersonally relevant risk factors like loneliness-either directly (e.g., by reducing feelings of being unloved and alone) or indirectly (e.g., by boosting well-being and its associated benefits, which can allay both the internal beliefs and the environmental conditions that can facilitate loneliness) - thereby protecting people from mental disorders.

\section{Positive Activities Facilitate the Coping Process}

Nolen-Hoeksema and Watkins (2011) note that environmental stressors can give rise to proximal risk factors (i.e., the distal risk factor of childhood trauma can trigger rumination) and also aggravate them (i.e., the recent loss of a job might intensify a ruminative pattern), thus engendering psychopathology. Accordingly, by intervening at various points in the risk-factor-to-disorder trajectory, adaptive coping with negative experiences or stressful transitions might thwart a downward spiral toward clinical symptoms. Evidence from the coping literature suggests that the positive emotions elicited by positive activities can be a key ingredient in the coping process, as they allow people to construe stressful situations more as a challenge than a threat, grant people the emotional wherewithal to sustain their coping efforts over time, and provide a needed time-out from an emotionally aversive situation (Folkman, 2008; Folkman \& Moskowitz, 2000). Indeed, positive affect is consistently associated with personal growth after traumatic or stressful experiences (e.g., adversarial growth), which in turn is associated with less subsequent distress (Linley \& Joseph, 2004).

Further evidence for the critical role of positive emotions during times of stress comes from research on resilience-an ability to bounce back and thrive in the face of negative experiences or circumstances. Studies indicate, for example, that positive emotions play an important role in the adaptive coping response of highly resilient people. Specifically, in the aftermath of 9/11, positive emotions buffered resilient participants from depression and stimulated personal growth (Fredrickson, Tugade, Waugh, \& Larkin, 2003). Similarly, those who felt positive emotions after a negative experience were able to find positive meaning in the experience (Tugade \& Fredrickson, 2004), a key coping strategy (Folkman \& Moskowitz, 2000). This work suggests that prompting people to engage in positive activities while undergoing a stressful experience might stimulate positive emotions that aid in productive coping and possibly avert downward spirals into clinical symptomatology. For example, chronic uncontrollable stress (e.g., looming layoffs at work) or acute social stress (e.g., bullying) may trigger an anxiety disorder in ruminators (NolenHoeksema \& Watkins, 2011), and positive activities could disrupt this trajectory by lessening distress and fostering effective coping.

Certain coping strategies (e.g., focusing on possible benefits of a stressful experience or creating positive events) have been found to generate positive emotions (Folkman, 2008; Folkman \& Moskowitz, 2000). We expect positive activities to be similarly effective in eliciting positive emotions to aid in the coping process. For example, gratitude in particular has been found to positively relate to adaptive coping (emotional and instrumental social support, positive reinterpretation, active coping, and planning) and negatively relate to maladaptive coping (disengagement, self-blame, substance abuse, and denial; Wood et al., 2007). In one experiment, people prompted to write gratefully about the positive consequences of an unpleasant event (vs. write about a neutral event or the details of the unpleasant event itself) reported feeling more closure and experiencing fewer intrusive thoughts and less emotional impact from the unpleasant memory (Watkins, Cruz, Holben, \& Kolts, 2008). Thus, people who express gratitude might be able to temper a negative event, therefore decreasing the likelihood that the event triggers or exacerbates proximal risk factors (e.g., see Columns B \& C, Row 1 of Table 1). The practice of gratitude is also likely to stimulate positive emotions, which can foster adaptive coping to other ongoing or future stressful life events, thus possibly forestalling a downward spiral into clinical symptoms (see Columns B \& C, Row 2 of Table 1). 


\section{Early Intervention}

Evidence suggests that well-being early in life is negatively related to psychopathology. Studies have found that higher levels of life satisfaction in adolescents are related to lower likelihood of poor mental health (Valois, Zullig, Huebner, \& Drane, 2004), contemplation of suicide (Valois et al., 2004), and substance abuse (Zullig, Valois, Huebner, Oeltman, \& Drane, 2001). In a longitudinal study of middle and high school students, greater life satisfaction at baseline $\left(M_{\text {Age }}=14.2\right.$ years $)$ moderated the effect of stressful situations and decreased the likelihood of later externalizing behaviors, thus serving as a protective factor (Suldo \& Huebner, 2004). These studies suggest that well-being in youth is related to positive developmental outcomes. We argue that, like their grown-up counterparts, happy children and adolescents are prone to practice positive activities, and these habits protect them from developing risk factors and eventual disorders.

Fortunately, it appears that positive activities can also be learned at an early age. Randomized controlled trials suggest that practicing positive activities can benefit well-being (Froh et al., 2008; Layous et al., 2012) and relationships (Layous et al., 2012) among youth. Early adolescents instructed to count their blessings for 2 weeks showed larger increases in well-being than those instructed to keep track of their daily hassles (Froh et al., 2008). In a follow-up study comparing the counting blessings activity with a neutral control (recalling daily events) over 2 weeks, children and adolescents who were low in positive affect at baseline benefitted the most from the positive activity at posttest and at a 2-month follow-up, thus indicating that gratitude exercises might particularly help those students who need a boost (Froh, Kashdan, Ozimkowski, \& Miller, 2009).

Similarly, in the study of classroom social ties described above, preadolescents were instructed either to keep track of their whereabouts or to perform kind acts weekly over 4 weeks (Layous et al., 2012). Both groups showed increases in life satisfaction, happiness, and positive affect, but students who engaged in kind acts were more likely to see increases in nominations from their peers as "someone you would like to be in school activities with" (a measure of peer acceptance) than those who kept track of their locations (Layous et al., 2012), thus indicating that positive activities can have positive effects on relationships, which, in turn, could benefit well-being even further. Finally, a recent 6-week intervention found that 16- and 17-year-old twins reported feeling happier, more grateful, and more connected to others after practicing gratitude and kindness than after engaging in neutral activities (Haworth et al., 2013). In sum, developmental research suggests that early well-being is protective against later risk factors for disorder and that youth can implement positive activities for both direct and ancillary benefits.

\section{Factors That Affect the Success of Positive Activities}

Although positive activities have been shown to lift well-being generally, a closer look at the literature reveals greater success under certain conditions. Specifically, features of the person (e.g., amount of effort mustered or her initial affective state), the activity (e.g., its dosage or inherent social support), and the interaction between person and activity (i.e., person-activity fit) impact how much well-being the activity produces (Lyubomirsky \& Layous, 2013). These factors, which can dampen or enhance the efficacy of the activity, deserve special attention in populations who are at risk for mental disorders. For example, could practices like gratitude or optimism be ineffective or even detrimental to those who have experienced childhood abuse or neglectful parenting? Might individuals who are hypervigilant or neurotic be better off starting with simple and stress-free activities? Accordingly, we consider whether positive activities can be judiciously "matched" to particular risk factors, thereby yielding the greatest gains in well-being.

\section{Person-Activity Fit}

Certain positive activities likely work better for certain people. Specifically, if a particular practice feels natural and enjoyable to a person, he or she will be more likely to feel intrinsically motivated to perform it (Deci \& Ryan, 2000). The importance of matching people's interests and values with their activities has been persuasively demonstrated in the goal pursuit literature. Specifically, the extent to which goal attainment influences well-being depends on the degree of goal-person fit (Sheldon \& Elliott, 1999). People put more effort into goals that match their interests and values (e.g., self-concordant goals) and are more likely to reap benefits from attaining them (Sheldon \& Elliott, 1999).

Because positive activities represent one type of goal pursuit (i.e., the goal of improving well-being), we posit that optimal person-activity fit will be associated with more intrinsic motivation-and, thus, greater effort-toward that activity. Research on positive activities has already shown that people who are more motivated to become happy, and who summon more effort into the practice of positive activities, garner the greatest benefits in wellbeing (Lyubomirsky, Dickerhoof, et al., 2011). Thus, we predict that people who practice activities best-suited to their interests, goals, and resources will show the biggest improvements in wellbeing. For example, some at-risk individuals might be particularly motivated to change negative patterns of thought (e.g., rumination) or behavior (e.g., perfectionism), although others may lack the resources or energy to initiate all but the most undemanding activities.

Preliminary evidence supports the importance of person-activity fit. For example, participants who indicated a preference for certain positive activities (i.e., they enjoyed them, benefited from them, and did not find them difficult to perform) were more likely to adhere to those activities and to show greater gains in well-being (Schueller, 2010; see also Parks \& Szanto, 2013). Similarly, participants who reported that an activity felt natural and enjoyable to them were more likely to practice the activity after the prescribed intervention period had lapsed, and were more likely to maintain their increases in happiness (Dickerhoof, 2007). Given the unique concerns of individuals at risk for mental health conditions-for example, those with biological vulnerabilities or childhood trauma-optimal risk factor-activity fit might be particularly important.

\section{Risk Factor-Activity Fit}

Certain positive activities may be uniquely effective in mitigating specific risk factors. For example, individuals who are high in negative affectivity or prone to ruminate could be helped by loving-kindness meditation because it redirects their negativity and tendency to dwell on problems into positive directions and pro- 
motes positive self-views. The practice of optimism is likely to be a direct antidote to a pessimistic attributional style, as this activity involves construing life events positively and charitably. Likewise, those with fragile self-concepts or low self-esteem might benefit from practicing acts of kindness because generosity reduces selffocus and bolsters self-confidence (Lyubomirsky, Sheldon et al., 2005; Otake, Shimai, Tanaka-Matsumi, Otsui, \& Fredrickson, 2006).

Conversely, particular risk factors could conceivably make it difficult for individuals to derive any benefit from particular positive activities. For example, when asked to visualize her dreams coming true (an activity designed to rehearse optimism), an individual high in reassurance-seeking might doubt her ability to accomplish her life goals. Likewise, although most people feel more grateful after completing a gratitude exercise, narcissistic individuals have actually been found to become more ungratefulperhaps because acknowledging others' contributions feels threatening (Kruse, Chancellor, Ruberton, \& Lyubomirsky, 2013). Thus, the presence of particular risk factors might blunt or dampen the benefits of practicing particular positive activities.

\section{Future Directions}

Although self-administered (Geraghty et al., 2010; Parks \& Szanto, 2013; Seligman et al., 2005) and individual and groupadministered (Fava, Rafanelli, Cazzaro, Conti, \& Grandi, 1998; Fava et al., 2005; Flückiger, Caspar, Holtforth, Willutzki, 2009; Seligman et al., 2006) positive interventions have shown success in increasing well-being and alleviating a range of clinical symptoms (e.g., depressive mood, body dissatisfaction, anxiety), to our knowledge, no prior studies of self-administered positive activities have specifically targeted individuals with either distal or proximal risk factors for disorder. More direct empirical support for our thesis that positive activities can mitigate risk factors could be obtained from positive activity interventions with at-risk individuals. Mediational analyses from such experiments could reveal whether increases in well-being - and its associated benefitsmediate the relationship between performing positive activities and decreases in proximal risk factors, whether positive activities act directly on proximal risk factors, or whether all three processes occur in tandem. In addition, testing various combinations of positive activities and risk factors could demonstrate optimal (or suboptimal) risk factor-activity fit.

Studies could also explore which positive activities - and under what conditions-best assist in the coping process, as well as the extent to which they decrease the likelihood that proximal risk factors devolve into disorder after stressful experiences. The most resource-intensive future research is likely to involve longitudinal positive activity interventions with very long follow-ups; such studies may be the only ones with the ability to show whether decreases in proximal risk factors-as well as reduction or prevention of conditions that trigger or amplify them-predict less psychopathology.

In addition, future studies could identify which moderators of the effects of proximal risk factors are most amenable to change by positive activities. For example, practicing kindness could help redirect a youth with a proclivity for sensation-seeking toward the "natural high" of acting prosocially and improve a strained relationship with his teacher (i.e., social stressor). Knowing the most consequential pathways would help clinicians and policymakers direct limited resources for optimal prevention of later psychopathology.

Researchers might consider testing self-administered positive activities along with established clinician-directed prevention efforts because of their unique advantages. For example, clinicians seeking to identify and assist individuals with risk factors often encounter resistance from stakeholders due to the stigma, inconvenience, and cost of seeking mental health treatment. Selfadministered positive activities, in contrast, can play a crucial role in population prevention strategies because they are relatively nonthreatening and inexpensive (Layous, Chancellor, Lyubomirsky, Wang, \& Doraiswamy, 2011). Finally, self-administered positive activities can "scale up" to address the needs of populations that would otherwise require the training and licensing of new mental health professionals and paraprofessionals.

\section{Final Words}

Tolstoy observes in Anna Karenina that "Happy families are all alike; every unhappy family is unhappy in its own way." For almost a century, clinical psychologists and psychiatrists have labored to differentiate, classify, and mitigate symptoms of mental health gone awry. Transdiagnostic models and heuristics that aid in their development (Nolen-Hoeksema \& Watkins, 2011) represent an exciting new direction for clinical psychology that promises to overcome the inherent difficulty of identifying all of the points of failure or opportunities for sabotage in a highly complex system.

A risk factor approach also complements work being conducted by our laboratory and others on the common antecedents and determinants of human flourishing. We hope that conceptualizing well-being-increasing activities as protective factors against mental health conditions will strengthen scientists' and clinicians' understanding of how such conditions develop - and can be prevented and ameliorated - as well as highlight yet another way that Nolen-Hoeksema's fruitful and prolific work has influenced countless researchers, students, and patients.

\section{References}

Aldao, A., Nolen-Hoeksema, S., \& Schweizer, S. (2010). Emotion regulation strategies across psychopathology: A meta-analytic review. Clinical Psychology Review, 30, 217-237. doi:10.1016/j.cpr.2009.11.004

Algoe, S. B., Gable, S. L., \& Maisel, N. C. (2010). It's the little things: Everyday gratitude as a booster shot for romantic relationships. Personal Relationships, 17, 217-233. doi:10.1111/j.1475-6811.2010.01273.x

Algoe, S. B., Haidt, J., \& Gable, S. L. (2008). Beyond reciprocity: Gratitude and relationships in everyday life. Emotion, 8, 425-429. doi: 10.1037/1528-3542.8.3.425

Boehm, J. K., Lyubomirsky, S., \& Sheldon, K. M. (2011). A longitudinal experimental study comparing the effectiveness of happiness-enhancing strategies in Anglo Americans and Asian Americans. Cognition \& Emotion, 25, 1263-1272. doi:10.1080/02699931.2010.541227

Boehm, J. K., Lyubomirsky, S., \& Sheldon, K. M. (2012). The role of need satisfying emotions in a positive activity intervention. Unpublished raw data.

Chancellor, J., Jacobs Bao, K., \& Lyubomirsky, S. (2013). Ripples of generosity in the workplace: The benefits of giving, getting, and glimpsing. Manuscript submitted for publication.

Chancellor, J., Layous, K., \& Lyubomirsky, S. (2013). Recalling positive events at work makes employees feel happier, move more, and chat less: 
A 6-week randomized controlled intervention at a Japanese workplace. Manuscript submitted for publication.

Cohen, G. L., Garcia, J., Apfel, N., \& Master, A. (2006). Reducing the racial achievement gap: A social-psychological intervention. Science, 313, 1307-1310. doi:10.1126/science.1128317

Cohen, G. L., Garcia, J., Purdie-Vaughns, V., Apfel, N., \& Brzustoski, P. (2009). Recursive processes in self-affirmation: Intervening to close the minority achievement gap. Science, 324, 400-403. doi:10.1126/science 1170769

Creswell, J. D., Welch, W., Taylor, S. E., Sherman, D. K., Gruenewald, T., \& Mann, T. (2005). Affirmation of personal values buffers neuroendocrine and psychological stress responses. Psychological Science, 16, 846-851. doi:10.1111/j.1467-9280.2005.01624.x

Cunningham, M. R. (1988a). Does happiness mean friendliness? Induced mood and heterosexual self-disclosure. Personality and Social Psychology Bulletin, 14, 283-297. doi:10.1177/0146167288142007

Cunningham, M. R. (1988b). What do you do when you're happy or blue? Mood, expectancies, and behavioral interest. Motivation and Emotion, 12, 309-331. doi:10.1007/BF00992357

Deci, E. L., \& Ryan, R. M. (2000). The "what" and "why" of goal pursuits: Human needs and the self-determination of behavior. Psychological Inquiry, 11, 227-268. doi:10.1207/S15327965PLI1104_01

Della Porta, M. D., Jacobs Bao, K., \& Lyubomirsky, S. (2012). Does supporting autonomy facilitate the pursuit of happiness? Results from an experimental longitudinal well-being intervention. Manuscript submitted for publication.

De Neve, J.-E., Diener, E., Tay, L., \& Xuereb, C. (2013). The objective benefits of subjective well-being. In J. Helliwell, R. Layard, \& J. Sachs (Eds.), World happiness report 2013 (pp. 54-79). New York, NY: UN Sustainable Development Solutions Network.

Dickerhoof, R. M. (2007). Expressing optimism and gratitude: A longitudinal investigation of cognitive strategies to increase well-being. Dissertation Abstracts International, 68, 4174 (UMI No. 3270426).

Diener, E., \& Seligman, M. E. (2002). Very happy people. Psychological Science, 13, 81-84. doi:10.1111/1467-9280.00415

Diener, E., Suh, E. M., Lucas, R. E., \& Smith, H. L. (1999). Subjective well-being: Three decades of progress. Psychological Bulletin, 125, 276-302. doi:10.1037/0033-2909.125.2.276

Dimidjian, S., Barrera, M., Jr., Martell, C., Muñoz, R. F., \& Lewinsohn, P. M. (2011). The origins and current status of behavioral activation treatments for depression. Annual Review of Clinical Psychology, 7, 1-38. doi:10.1146/annurev-clinpsy-032210-104535

Dunn, E. W., Aknin, L. B., \& Norton, M. I. (2008). Spending money on others promotes happiness. Science, 319, 1687-1688. doi:10.1126/ science. 1150952

Emmons, R. A., \& McCullough, M. E. (2003). Counting blessings versus burdens: An experimental investigation of gratitude and subjective wellbeing in daily life. Journal of Personality and Social Psychology, 84, 377-389. doi:10.1037/0022-3514.84.2.377

Fava, G. A., Rafanelli, C., Cazzaro, M., Conti, S., \& Grandi, S. (1998). Well-being therapy. A novel psychotherapeutic approach for residual symptoms of affective disorders. Psychological Medicine, 28, 475-480. doi:10.1017/S0033291797006363

Fava, G. A., Ruini, C., Rafanelli, C., Finos, L., Salmaso, L., Mangelli, L., $\&$ Sirigatti, S. (2005). Well-being therapy of generalized anxiety disorder. Psychotherapy and Psychosomatics, 74, 26-30. doi:10.1159/ 000082023

Flückiger, C., Caspar, F., Holtforth, M. G., \& Willutzki, U. (2009). Working with patients' strengths: A microprocess approach. Psychotherapy Research, 19, 213-223. doi:10.1080/10503300902755300

Folkman, S. (2008). The case for positive emotions in the stress process. Anxiety, Stress \& Coping, 21, 3-14. doi:10.1080/10615800701740457
Folkman, S., \& Moskowitz, J. T. (2000). Stress, positive emotion, and coping. Current Directions in Psychological Science, 9, 115-118. doi: 10.1111/1467-8721.00073

Fredrickson, B. L. (1998). What good are positive emotions? Review of General Psychology, 2, 300-319. doi:10.1037/1089-2680.2.3.300

Fredrickson, B. L. (2001). The role of positive emotions in positive psychology. American Psychologist, 56, 218-226. doi:10.1037/0003066X.56.3.218

Fredrickson, B. L. (2004). Gratitude, like other positive emotions, broadens and builds. In R. A. Emmons \& M. E. McCullough (Eds.), The psychology of gratitude (pp. 145-166). New York, NY: Oxford University Press. doi:10.1093/acprof:oso/9780195150100.003.0008

Fredrickson, B. L., Cohn, M. A., Coffey, K. A., Pek, J., \& Finkel, S. M. (2008). Open hearts build lives: Positive emotions, induced through loving-kindness meditation, build consequential personal resources. Journal of Personality and Social Psychology, 95, 1045-1062. doi: 10.1037/a0013262

Fredrickson, B. L., \& Joiner, T. (2002). Positive emotions trigger upward spirals toward emotional well-being. Psychological Science, 13, 172175. doi:10.1111/1467-9280.00431

Fredrickson, B. L., Mancuso, R. A., Branigan, C., \& Tugade, M. M. (2000). The undoing effect of positive emotions. Motivation and Emotion, 24, 237-258. doi:10.1023/A:1010796329158

Fredrickson, B. L., Tugade, M. M., Waugh, C. E., \& Larkin, G. R. (2003). What good are positive emotions in crisis? A prospective study of resilience and emotions following the terrorist attacks on the United States on September 11th, 2001. Journal of Personality and Social Psychology, 84, 365-376. doi:10.1037/0022-3514.84.2.365

Froh, J. J., Kashdan, T. B., Ozimkowski, K. M., \& Miller, N. (2009). Who benefits the most from a gratitude intervention in children and adolescents? Examining positive affect as a moderator. The Journal of Positive Psychology, 4, 408-422. doi:10.1080/17439760902992464

Froh, J. J., Sefick, W. J., \& Emmons, R. A. (2008). Counting blessings in early adolescents: An experimental study of gratitude and subjective well-being. Journal of School Psychology, 46, 213-233. doi:10.1016/j .jsp.2007.03.005

Geraghty, A. W., Wood, A. M., \& Hyland, M. E. (2010). Attrition from self-directed interventions: Investigating the relationship between psychological predictors, intervention content and dropout from a body dissatisfaction intervention. Social Science \& Medicine, 71, 30-37. doi:10.1016/j.socscimed.2010.03.007

Guerra, N. G., \& Bradshaw, C. P. (2008). Core competencies to prevent problem behaviors and promote positive youth development. San Francisco, CA: Jossey-Bass.

Haworth, C., Nelson, S. K., Layous, K., Bao, K. J., Lyubomirsky, S., \& Plomin, R. (2013). The Twins Wellbeing Intervention Study (TWIST): Results of a genetically sensitive online intervention. Manuscript in preparation.

Heinrich, L. M., \& Gullone, E. (2006). The clinical significance of loneliness: A literature review. Clinical Psychology Review, 26, 695-718. doi:10.1016/j.cpr.2006.04.002

Isen, A. M., Daubman, K. A., \& Nowicki, G. P. (1987). Positive affect facilitates creative problem solving. Journal of Personality and Social Psychology, 52, 1122-1131. doi:10.1037/0022-3514.52.6.1122

Jose, P. E., Lim, B. T., \& Bryant, F. B. (2012). Does savoring increase happiness? A daily diary study. The Journal of Positive Psychology, 7, 176-187. doi:10.1080/17439760.2012.671345

King, L. A. (2001). The health benefits of writing about life goals. Personality and Social Psychology Bulletin, 27, 798-807. doi:10.1177/ 0146167201277003

Krueger, R. F., Hicks, B. M., \& McGue, M. (2001). Altruism and antisocial behavior: Independent tendencies, unique personality correlates, distinct etiologies. Psychological Science, 12, 397-402. doi:10.1111/1467-9280 .00373 
Kruse, E., Chancellor, J., Ruberton, P. M., \& Lyubomirsky, S. (2013). An upward spiral between gratitude and humility. Manuscript submitted for publication.

Lambert, N. M., \& Fincham, F. D. (2011). Expressing gratitude to a partner leads to more relationship maintenance behavior. Emotion, 11, 52-60. doi: $10.1037 / \mathrm{a} 0021557$

Lasgaard, M., Goossens, L., Bramsen, R. H., Trillingsgaard, T., \& Elklit, A. (2011). Different sources of loneliness are associated with different forms of psychopathology in adolescence. Journal of Research in Personality, 45, 233-237.

Layous, K., Chancellor, J., Lyubomirsky, S., Wang, L., \& Doraiswamy, P. M. (2011). Delivering happiness: Translating positive psychology intervention research for treating major and minor depressive disorders. The Journal of Alternative and Complementary Medicine, 17, 675-683. doi:10.1089/acm.2011.0139

Layous, K., Lee, H. C., Choi, I., \& Lyubomirsky, S. (2013). Culture matters when designing a successful positive activity: A comparison of the United States and South Korea. Journal of Cross-Cultural Psychology, 44, 1294-1303.

Layous, K., Nelson, S. K., \& Lyubomirsky, S. (2013). What is the optimal way to deliver a positive activity intervention? The case of writing about one's best possible selves. Journal of Happiness Studies, 14, 635-654. doi:10.1007/s10902-012-9346-2

Layous, K., Nelson, S. K., Oberle, E., Schonert-Reichl, K. A., \& Lyubomirsky, S. (2012). Kindness counts: Prompting prosocial behavior in preadolescents boosts peer acceptance and well-being. PLOS ONE, 7, e51380. doi:10.1371/journal.pone.0051380

Linley, P. A., \& Joseph, S. (2004). Positive change following trauma and adversity: A review. Journal of Traumatic Stress, 17, 11-21. doi: 10.1023/B:JOTS.0000014671.27856.7e

Lyubomirsky, S. (2001). Why are some people happier than others?: The role of cognitive and motivational processes in well-being. American Psychologist, 56, 239-249. doi:10.1037/0003-066X.56.3.239

Lyubomirsky, S. (2008). The how of happiness: A scientific approach to getting the life you want. New York, NY: The Penguin Press.

Lyubomirsky, S., Boehm, J. K., Kasri, F., \& Zehm, K. (2011). The cognitive and hedonic costs of dwelling on achievement-related negative experiences: Implications for enduring happiness and unhappiness. Emotion, 11, 1152-1167. doi:10.1037/a0025479

Lyubomirsky, S., Caldwell, N. D., \& Nolen-Hoeksema, S. (1998). Effects of ruminative and distracting responses to depressed mood on retrieval of autobiographical memories. Journal of Personality and Social Psychology, 75, 166-177. doi:10.1037/0022-3514.75.1.166

Lyubomirsky, S., Dickerhoof, R., Boehm, J. K., \& Sheldon, K. M. (2011). Becoming happier takes both a will and a proper way: An experimental longitudinal intervention to boost well-being. Emotion, 11, 391-402. doi:10.1037/a0022575

Lyubomirsky, S., King, L., \& Diener, E. (2005). The benefits of frequent positive affect: Does happiness lead to success? Psychological Bulletin, 131, 803-855. doi:10.1037/0033-2909.131.6.803

Lyubomirsky, S., \& Layous, K. (2013). How do simple positive activities increase well-being? Current Directions in Psychological Science, 22, 57-62. doi:10.1177/0963721412469809

Lyubomirsky, S., \& Nolen-Hoeksema, S. (1995). Effects of self-focused rumination on negative thinking and interpersonal problem-solving. Journal of Personality and Social Psychology, 69, 176-190.

Lyubomirsky, S., Sheldon, K. M., \& Schkade, D. (2005). Pursuing happiness: The architecture of sustainable change. Review of General Psychology, 9, 111-131. doi:10.1037/1089-2680.9.2.111

Lyubomirsky, S., Tucker, K. L., Caldwell, N. D., \& Berg, K. (1999). Why ruminators are poor problem solvers: Clues from the phenomenology of dysphoric rumination. Journal of Personality and Social Psychology, 77, 1041-1060. doi:10.1037/0022-3514.77.5.1041
McCullough, M. E., Emmons, R. A., \& Tsang, J. (2002). The grateful disposition: A conceptual and empirical topography. Journal of Personality and Social Psychology, 82, 112-127. doi:10.1037/0022-3514.82.1 .112

Myers, D. G. (2000). The funds, friends, and faith of happy people. American Psychologist, 55, 56-67. doi:10.1037/0003-066X.55.1.56

National Institute of Health. (2008). National healthcare quality report. Retrieved from www.ahrq.gov/qual/qrdr08.htm

Nelson, S. K., Fuller, J. A. K., Choi, I., \& Lyubomirsky, S. (2013). Beyond self-protection: Self-affirmation boosts well-being. Manuscript submitted for publication.

Nolen-Hoeksema, S. (1991). Responses to depression and their effects on the duration of depressive episodes. Journal of Abnormal Psychology, 100, 569-582. doi:10.1037/0021-843X.100.4.569

Nolen-Hoeksema, S., \& Watkins, E. R. (2011). A heuristic for developing transdiagnostic models of psychopathology: Explaining multifinality and divergent trajectories. Perspectives on Psychological Science, 6, 589-609. doi:10.1177/1745691611419672

Otake, K., Shimai, S., Tanaka-Matsumi, J., Otsui, K., \& Fredrickson, B. L. (2006). Happy people become happier through kindness: A counting kindnesses intervention. Journal of Happiness Studies, 7, 361-375. doi:10.1007/s10902-005-3650-z

Ouellette, J. A., \& Wood, W. (1998). Habit and intention in everyday life: The multiple processes by which past behavior predicts future behavior Psychological Bulletin, 124, 54-74. doi:10.1037/0033-2909.124.1.54

Parks, A. C., \& Szanto, R. K. (2013). Assessing the efficacy and effectiveness of a Positive Psychology based self-help book. Terapia Psicológica, 31, 141-149. doi:10.4067/S0718-48082013000100013

Scheier, M. F., \& Carver, C. S. (1993). On the power of positive thinking: The benefits of being optimistic. Current Directions in Psychological Science, 2, 26-30. doi:10.1111/1467-8721.ep10770572

Schueller, S. M. (2010). Preferences for positive psychology exercises. The Journal of Positive Psychology, 5, 192-203. doi:10.1080/ 17439761003790948

Seligman, M. E., Rashid, T., \& Parks, A. C. (2006). Positive psychotherapy. American Psychologist, 61, 774-788. doi:10.1037/0003-066X.61.8 774

Seligman, M. E. P., Steen, T. A., Park, N., \& Peterson, C. (2005). Positive psychology progress: Empirical validation of interventions. American Psychologist, 60, 410-421. doi:10.1037/0003-066X.60.5.410

Sheldon, K. M., Abad, N., Ferguson, Y., Gunz, A., Houser-Marko, L., Nichols, C. P., \& Lyubomirsky, S. (2010). Persistent pursuit of need satisfying goals leads to increased happiness: A 6-month experimental longitudinal study. Motivation and Emotion, 34, 39-48. doi:10.1007/ s11031-009-9153-1

Sheldon, K. M., Boehm, J. K., \& Lyubomirsky, S. (2012). Variety is the spice of happiness: The hedonic adaptation prevention (HAP) model. In I. Boniwell \& S. David (Eds.), Oxford handbook of happiness (pp. 901-914). Oxford, UK: Oxford University Press.

Sheldon, K. M., \& Elliot, A. J. (1999). Goal striving, need satisfaction, and longitudinal well-being: The self-concordance model. Journal of Personality and Social Psychology, 76, 482-497. doi:10.1037/0022-3514 .76.3.482

Sheldon, K. M., \& Lyubomirsy, S. (2006). How to increase and sustain positive emotions: The effect of expressing gratitude and visualizing best possible selves. The Journal of Positive Psychology, 1, 73-82. doi:10.1080/17439760500510676

Sherman, D. K., Bunyan, D. P., Creswell, J. D., \& Jaremka, L. M. (2009). Psychological vulnerability and stress: The effects of self-affirmation on sympathetic nervous system responses to naturalistic stressors. Health Psychology, 28, 554-562. doi:10.1037/a0014663

Sherman, D. K., \& Cohen, G. L. (2006). The psychology of self-defense: 
Self-affirmation theory. In M. P. Zanna (Ed.), Advances in experimental social psychology (Vol. 38, pp. 183-242). San Diego, CA: Academic Press.

Sin, N. L., \& Lyubomirsky, S. (2009). Enhancing well-being and alleviating depressive symptoms with Positive Psychology Interventions: A practice friendly meta-analysis. Journal of Clinical Psychology, 65, 467-487. doi:10.1002/jclp.20593

Steele, C. (1988). The psychology of self-affirmation: Sustaining the integrity of the self. In L. Berkowitz (Ed.), Advances in experimental social psychology (Vol. 21, pp. 261-302). New York, NY: Academic Press. doi:10.1016/S0065-2601(08)60229-4

Suldo, S. M., \& Huebner, E. S. (2004). Does life satisfaction moderate the effects of stressful life events on psychopathological behavior during adolescence? School Psychology Quarterly, 19, 93-105. doi:10.1521/ scpq.19.2.93.33313

Tugade, M. M., \& Fredrickson, B. L. (2004). Resilient individuals use positive emotions to bounce back from negative emotional experiences. Journal of Personality and Social Psychology, 86, 320-333. doi: 10.1037/0022-3514.86.2.320

Valois, R. F., Zullig, K. J., Huebner, E. S., \& Drane, J. W. (2004). Life satisfaction and suicide among high school adolescents. Social Indicators Research, 66, 81-105. doi:10.1023/B:SOCI.0000007499.19430.2f

Watkins, P. C., Cruz, L., Holben, H., \& Kolts, R. L. (2008). Taking care of business? Grateful processing of unpleasant memories. The Journal of Positive Psychology, 3, 87-99. doi:10.1080/17439760701760567
Watkins, P. C., Woodward, K., Stone, T., \& Kolts, R. L. (2003). Gratitude and happiness: Development of a measure of gratitude, and relationships with subjective well-being. Social Behavior and Personality, 31, 431451. doi:10.2224/sbp.2003.31.5.431

Waugh, C. E., \& Fredrickson, B. L. (2006). Nice to know you: Positive emotions, self-other overlap, and complex understanding in the formation of new relationships. The Journal of Positive Psychology, 1, 93106. doi:10.1080/17439760500510569

Weissberg, R. P., Kumpfer, K. L., \& Seligman, M. E. (2003). Prevention that works for children and youth: An introduction. American Psychologist, 58, 425-432. doi:10.1037/0003-066X.58.6-7.425

Wood, A. M., Maltby, J., Gillett, R., Linley, P. A., \& Joseph, S. (2008). The role of gratitude in the development of social support, stress, and depression: Two longitudinal studies. Journal of Research in Personality, 42, 854-871. doi:10.1016/j.jrp.2007.11.003

World Health Organization. (2004). The global burden of disease: 2004 update. Retrieved from http://www.who.int/healthinfo/global_burden_ disease/2004_report_update

Zullig, K. J., Valois, R. F., Huebner, E. S., Oeltmann, J. E., \& Drane, J. W. (2001). Relationship between perceived life satisfaction and adolescents' substance abuse. Journal of Adolescent Health, 29, 279-288. doi: 10.1016/S1054-139X(01)00269-5

Received April 20, 2013

Revision received August 21, 2013 Accepted September 18, 2013 